\title{
The effects of certain angioneogenesis inhibitors in experimental endometriosis in rats
}

\author{
Barbe A., Berbets A., Davydenko I., Yuzko V., Yuzko O. \\ Bukovinian State Medical University, Chernivtsi, Ukraine \\ e-mail: adryanbarbe@gmail.com
}

\section{ABSTRACT}

The pathogenetic theory of retrograde outflow of endometrial cells into the peritoneal cavity at endometriosis is gaining an increasing support. Adequate blood supply and angioneogenesis play an important role in successful implantation and occurrence of ectopic foci. VEGF plays an important role in this process. Determination of the pathways affecting the activity of this factor seems to be promising in terms of its effect produced on the early pathogenetic links of endometriosis.

OBJECTIVES: to determine the effectiveness of dopamine agonist cabergoline and highly selective COX-2 inhibitor celecoxib in an experimental model of external genital endometriosis in rats.

METHODS. 83 outbred white female rats of Rattus Norvegicus Wistar were involved in the experiment. Experimental induction of endometriosis was performed by surgery and implantation of the autologous uterine fragments. The type and volume of experimental endometriosis lesions on the peritoneum of experimental animals were evaluated macroscopically as well as their hystologic examination were performed.

RESULTS. Administration of a dopamine receptor agonist as a VEGF inhibitor separately was found to produce a pronounced inhibitory effect on ectopic endometrioid formation. However, the use of a dopamine receptor agonist in combination with a highly selective COX-2 inhibitor does not lead to potentiation or summation of their effects. At the same time, the use of COX-2 inhibitor alone has shown significantly lower efficacy than using the dopamine receptor agonist as a VEGF inhibitor.

CONCLUSION. At experimental endometriosis in rats, dopamine agonists and highly selective COX-2 inhibitors were found to be one of VEGF inhibitors available.

KEY WORDS: experimental endometriosis; angioneogenesis; VEGF; dopamine agonist; COX-2 inhibitor; cabergoline; celecoxib

Endometriosis is a chronic benign hormone-dependent condition when the endometrial tissue, identical with the endometrium by its morphological and functional properties, grows outside the borders of the uterine mucous membrane. It leads to clinical symptoms able to affect the physical condition, psychological status and social status of the patient [1-4]. According to research data endometriosis is diagnosed in $5-10 \%$ of the female population. There are approximately 176 million women with endometriosis in the world, mainly of a reproductive age.

Nowadays, certain isolated reports in scientific literature are found concerning proliferation suppression, as well as regression of tumors and endometrioid heterotopias under the influence of some dopamine agonists [5], as well as COX-2 inhibitors [6, 7]. Pathogenetic theory of retrograde outflow of endometrial cells into the peritoneal cavity is gaining an increasing support $[8,9]$. And the peritoneal fluid, namely the state of the pro- and anti-inflammatory cytokines of the peritoneal fluid, plays a key role. The implantation of endometrium cells results from balance disorder and excretion of growth factors. Adequate blood supply and neoangiogenesis play an important role in successful implantation and occurrence of ectopic foci [10-12].

Considering the above, it can be suggested that one of the promising areas of conservative treatment of external genital endometriosis is the effect produced on one of the pathogenetic links, namely, inhibition of angiogenesis by the use of dopamine agonists and COX-2 inhibitors [13].

Angiogenesis is a complex process of formation of new blood vessels from the vessels existed before. This process plays a fundamental role in the reproduction, development and healing of wounds. In adults, endothelial proliferation is a strictly regulated process based on the balance between angiogenic and angiostatic factors which are activated in case 
of necessity and subsequently completely inhibited when necessary [14, 15]. Cases of increased endothelial cell proliferation rate are often associated with tumors and their development [16], which are known to be dependent on angiogenesis for growth and metastasis [17]. The survival of endometrioid implants in the abdominal cavity depends on the formation of blood supply to provide oxygen and nutrients to the developing lesions. Pathomorphological examination of endometriosis foci determines their dense vascularization $[15,18]$. Similar to the process of tumor vascularization, endometriosis can utilize the mechanisms of angiogenesis and vasculogenesis to form its own vascular network to maintain viability.

It should be supposed that endometrial fragments separated from the uterine endometrium may be the carriers of angiogenic potential. The human endometrium, which consists of the functional and basal layer, is a unique organ that undergoes proliferation, differentiation and regeneration at each menstrual cycle under the regulation of steroid hormones of the ovaries - estrogens and progesterone. In addition to endometrial growth, the vascular bed of the endometrium undergoes proliferation and regeneration at every cycle under the influence of ovarian steroids, especially estradiol (E2). Shifren et al. [19] identified the increased expression of vascular endothelial growth factor (VEGF) mRNA in the functional layer of the endometrium in the proliferative and secretory phase of the menstrual cycle, indicating the involvement of angiogenesis for proliferation and regeneration. The same study found that E2 is responsible for stimulating VEGF expression in isolated human endometrial cells, and E2 administration increased VEGF mRNA expression compared to endometrial cells without E2 stimulus. Endometriosis can be suggested to result from implantation of endometrial fragments into the abdominal cavity with subsequent activation of cellular aggression and proliferation mechanisms.

VEGF appears to play an important role in supporting angiogenesis at endometriosis. It is a vasoactive substance which is involved in various normal physiological processes, including wound healing and endometrial revascularization, mediating endothelial proliferation and migration. In oncogenesis VEGF concentration usually correlates with increased blood supply in various tissue types that are associated with the tumor [20]. In normal endometrium, elevation of VEGF mRNA levels and expression of the corresponding proteins can be caused by hypoxia [21]. No wonder that the peritoneal fluid of women with the last stages of endometriosis contains higher VEGF concentrations than that of women with initial stages of endometriosis or healthy women [22]. Various sources of VEGF have been identified, including endometrioid lesions [23] and peritoneal fluid macrophages that increase VEGF expression when treated with ovarian steroids such as E2 and progesterone [24], transforming the notion that VEGF is involved in angiogenesis associated with endometrial lesions [25].

VEGF, also known as VEGF-A, is a secretory cytokine structurally related to platelet-derived growth factor (PDGF), which mediates physiological and tumor angiogenesis [26-29]. In mice a complete damage of this factor is lethal and causes severe cardiovascular abnormalities [ 30 , 31]. In vitro it promotes endothelial cell proliferation, migration, and vascular tube formation [32]. In various in vivo models it induces a strong angiogenic response [33]. At adulthood VEGF is involved in wound healing, menstruation, pregnancy and blood pressure support [29]. During physiological angiogenesis, it is produced by various cell types, including neutrophils, platelets, and macrophages [29].

Currently there are the following ways of VEGF inhibition: (1) neutralizing monoclonal antibodies against VEGF and VEGFR; (2) small-molecule VEGF receptor tyrosine kinase inhibitors; (3) soluble VEGF receptors (VEGF-Trap) and (4) ribozymes [34]. In addition to the above mentioned VEGF inhibition pathways which are widely discussed in clinical oncology, there is the evidence of possibile inhibition of VEGF-induced angiogenesis by using dopamine neurotransmitter [35]. Bacic et al [36] reported that dopaminergic receptors are linked to adenylyl cyclase in the human cerebral microvascular endothelium. Dopamine is a catecholamic neurotransmitter involved in pathogenesis of both Parkinson's disease and development of schizophrenia [37-40]. Dopamine and its derivative molecules have shown inhibitory potential in several types of malignant tumors in mice, and its effects have been explained by inhibition of tumor cell proliferation, stimulation of immunity etc. [41-44]. Recent studies demonstrate the presence of $\mathrm{D} 2$ dopamine receptors on endothelial cells $[45,46]$, which may affect angiogenesis. It is this mechanism that is likely to be important in inhibiting tumorigenesis [47, 48], as VEGF is the most important angiogenic cytokine in tumors and in other types of pathological angiogenesis $[49,50]$.

VEGF is believed to induce angiogenesis by involving VEGF receptor type 2 (VEGFR-2), which leads to its phosphorylation and downstream signaling events series [51]. $1 \mu \mathrm{M}$ dopamine was found to inhibit VEGFinduced phosphorylation of VEGFR-2 in vitro. D2 bromocriptine and quinpyrrole agonists similarly inhibit VEGF-induced phosphorylation of VEGFR-2 [52-54]. Dopamine is indicated to stimulate internalization of VEGFR-2 surface, probably by endocytosis, leaving less VEGFR-2 on the surface to interact with VEGF [52-54]. Thus, the inhibitory effect of dopamine on VEGF-induced angiogenesis is explained by its action at the early signaling stage. It is important to note that dopamine inhibits angiogenesis mediated by VEGF, but probably does not affect angiogenesis mediated by other mechanisms [54].

VEGF is not the only way to activate angiogenesis. There are alternative activation pathways, such as through COX-2. COX-2 converts arachidonic acid into prostaglandin $\mathrm{H} 2$, which can be enzymatically converted into five major prostanoids: prostaglandin E2, prostaglandin D2, prostaglandin 12 (prostacyclin), prostaglandin F2a and thromboxane. COX-2 and prostaglandin E2 have been previously demonstrated to induce angiogenesis, but most studies indicate an indirect role by means of stimulating other proangiogenic growth factors [55]. In addition to indirect effects, hypothetically, the COX-2 / PGE2 pathway may play a direct role in stimulating angiogenesis through VEGF-independent paracrine mechanisms that directly affect endothelial cells [56]. Certain studies have shown that COX-2 regulates VEGF-induced angiogenesis, and also that VEGF controls COX-2-induced angiogenesis, indicating reciprocity between these pathways $[57,58]$. The ability of COX-2/PGE2 pathway to induce VEGFindependent angiogenesis suggests that this pathway may promote angiogenesis when VEGF pathway is blocked.

Moreover, scientific literature contains certain information concerning suppression of VEGF-induced phosphorylation of type 2 VEGF receptor by dopamine [59-61], occurring due to phosphorylation of tyrosine phosphatase 2 [62], and therefore, its inactivation.

OBJECTIVE OF THE STUDY: to determine the effectiveness of dopamine agonist cabergoline and highly selective COX-2 inhibitor celecoxib in an experimental model of external genital endometriosis in rats.

\section{MATERIAL AND METHODS}

The experiment involved 83 outbred, sexually mature, nulliparous white Rattus Norvegicus Wistar rats weighing 170-200 g, 14-17 weeks of age. All the manipulations on animals were carried out in accordance with the recommendations of the UNESCO Intergovernmental Committee on Bioethics (IGBC). All the procedures and experiments of this study respect the ethical standards in the Helsinki Declaration of 1975, as revised in 2008 [5], as well as the national law. All institutional and national guidelines for the care and use of laboratory animals were followed.

At the end of the adaptation period, starting from the first day of the experiment, rats were injected subcutaneously in the back with $0.06 \mathrm{mg} / \mathrm{kg}$ body weight of estradiol valerate. Estradiol valerate injection at the dose of $0.06 \mathrm{mg} / \mathrm{kg}$ was repeated on the third day of the experiment.

On the fourth day of the experiment, experimental induction of endometriosis was performed by means of surgery and implantation of an autologous uterine fragment using the method described by A. Golan et al. [63] and T. Hirata et al. [64]. After awakening from ketamine-xylazine intraperitoneal anesthesia, rats were randomly and evenly divided into groups. Rats of all the groups were treated with estrogenic hormonal 
support in the form of daily subcutaneous injections of $0.03 \mathrm{mg} / \mathrm{kg}$ body weight of estradiol valerate until the last day of the experiment.

In the first experimental group comprising 21 rats, dopamine receptors agonist cabergoline (ATC: G02CB03; Dostinex ${ }^{\circledR}$, Pfizer Italia S.r.I.) was used as a subcutaneous injection in the dose of $0.075 \mathrm{mg} / \mathrm{kg}$ body weight daily. In the second experimental group including 19 rats, a dopamine receptor agonist and a COX-2 inhibitor were administered as a single subcutaneous injection of cabergoline in the dose of $0.075 \mathrm{mg} / \mathrm{kg}$ of animal body weight and celecoxib (ATX: L01XX33, M01AH01; Celebrex ${ }^{\circledR}$, Pfizer Inc.) in the dose of $30 \mathrm{mg} / \mathrm{kg}$ of animal body weight daily. In the third experimental group of 20 rats, the COX-2 inhibitor celecoxib was administered as a subcutaneous injection in the dose of $30 \mathrm{mg} / \mathrm{kg}$ of animal body weight daily. In the fourth, the control group, which comprised 20 rats, nothing more than estrogen support has been applied.

In the first, second and third experimental groups, drugs were administered from the $12^{\text {th }}$ day of the experiment (from the $8^{\text {th }}$ day after surgery) to the end of the experiment (the $25^{\text {th }}$ day of the experiment, the $21^{\text {st }}$ day after surgery). On the $26^{\text {th }}$ day of the experiment $\left(22^{\text {nd }}\right.$ day after surgery) euthanasia was performed by decapitation using thiopental anesthesia in the dose of $5.7 \mathrm{mg} / \mathrm{kg}$ of the body weight.

The presence and type of lesions were evaluated macroscopically: cysts filled with dark fluid, cysts filled with light fluid, lesions in the form of solid tissue, or the absence of macroscopic signs of lesions.

Using the office transparent millimeter ruler the smallest and largest diameters of lesions were measured. The following formula was used to determine the volume of lesions: where $d_{1}$ and $d_{2}-$ are the smallest and largest diameters of lesion respectively.
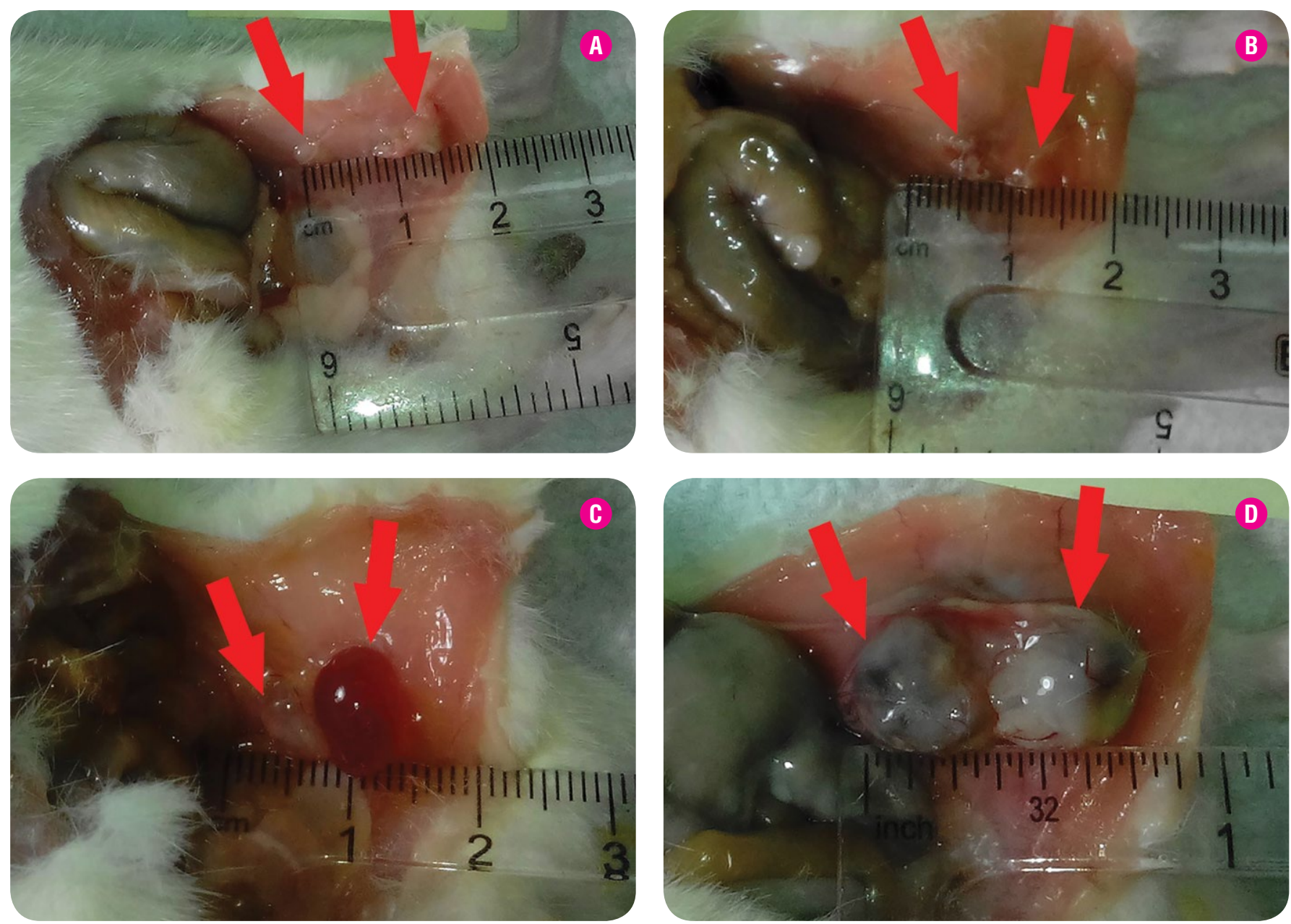

$$
V=\frac{2}{3} * \pi *\left(\left(\frac{d_{1}+d_{2}}{4}\right)^{3}\right)
$$

Sampling of the material for morphological studies was performed according to standard requirements for making histological preparations. The tissue fragments after washing in distilled water were fixed in 10-12\% solution of neutral formalin, after which they were transferred to 3-5\% solution of neutral formalin, where they were stored. The preparations were dehydrated by sequentially running the objects through ethanol of increasing concentration.

Subsequently, paraffin embedded blocks were made and 3 to $5 \mu \mathrm{m}$ thick histologic sections were perfomed using a microtome. To obtain differentiated polychromy, the tissue was stained with hematoxylin-eosin. Histological sections were examined, analyzed and photographed using a computer-based image analysis system consisting of an CX-21 light microscope (Olympus, Japan) and C450 digital camera (Olympus, Japan).

Estimation of optical density and the area calculations of microscopic structures was performed using free-licensed software ImageJ, ver. $1.50 \mathrm{~b}$ (NIH, USA). The optical density of cytoplasm and nuclei of secretory epithelial cells was estimated using 0-255 RGB gradation ( 0 - black color, 255 - white color).

The results were statistically processed by MedCalc 15.8 software (MedCalc Software bvba, Belgium) using Mann-Whitney U-test and descriptive statistics analysis. Data were presented as mean +/- standard deviation (SD). Graph data were presented as clustered bar chart and box and whisker charts.

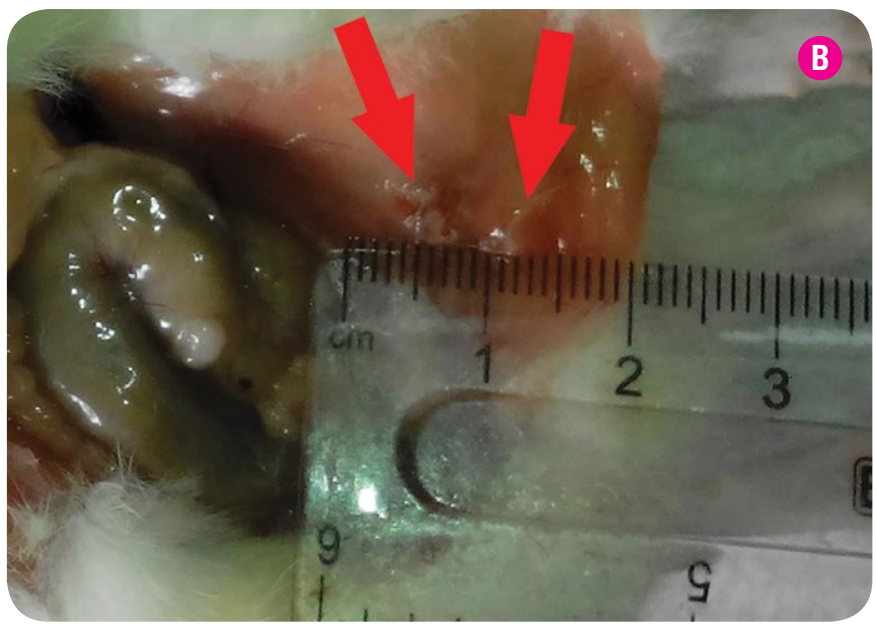

Fig. 1. Macroscopic view of ectopic uterine tissue on the peritoneum when using cabergoline only (A), celecoxib (B) or combination of cabergoline and celecoxib (C) compared to control group (D). Arrows indicate implant growth sites. 


\section{RESULTS AND DISCUSSION}

Most current theories of endometriosis are based on the theory of Sampson's retrograde menstruation. However, an open question remains why retrograde menstruation occurs in $90 \%$ of women of reproductive age, while the incidence of endometriosis is several times less. Among the contributing factors for the implantation of eutopic endometrium to the peritoneum, we have identified VEGF as one of the major contributors to the growth of heterotopias. Dopamine agonists and highly selective COX-2 inhibitors have been identified as one of the available VEGF inhibitors. In order to determine the effectiveness of their use, we created an experimental model of endometriosis in rats.

Macroscopic examination of endometrioid foci was performed immediately after euthanasia, after opening the abdominal cavity of a rat using $\mathrm{U}$-shaped incision. Considering the fact that the only reliable method of diagnosis of endometriosis is visual identification of foci during laparoscopy with subsequent histological verification, it is advisable to visualize and perform morphometry in an experimental model of endometriosis. Based on morphometry, data the volume of lesions was determined, which is another parameter of objectification when conducting statistical research. Due to the fact that two flaps of their own uterine horn were transplanted to each animal, the number of observed cases was doubled in relation to the number of animals in this group.

The morphological data we have obtained coincide with those of other researchers who used a similar technique. Thus, Elgamal et al. [65] describes ectopic endometrioid lesions macroscopically in the form of cysts filled with fluid, and the histological picture obtained by us completely corresponds to the described one by Rezende et al. [66], Neto et al. [67] and Amaral et al. [68] (Fig. 1).

While comparing the types of lesions (Fig. 2), we determined that the least cystic endometrioid formation occurred when cabergoline was used. The use of celecoxib alone and in combination with cabergoline showed less effectiveness concerning this parameter.

While comparing the volume of lesions (Fig. 3), we found that the best results were obtained when cabergoline was used separately. The volume of lesions after cabergoline administration is almost 9 times smaller than that in the control group. It should be noted that the volume of lesions after administration of cabergoline + celecoxib combination is almost 3.5 times smaller than that in the control. When celecoxib is used separately, there is also a significant difference in the volume of lesions (celecoxib reduces the size of lesions), but less pronounced (slightly more than 2 times).

One of the indirect signs of vascular and capillary proliferation, as well as a sign of successful implantation of ectopic endometrium, is the growth of the glandular epithelium and its secretory activity.

During microscopic examination of endometrioid lesions, we observed glandular secreting epithelium oriented by the secretory pole towards the cystic cavity. The stroma of the glands is found lower, which respectively lie on the myometrial basis (which was preserved during transplantation). We observed the viability and functional activity of the glandular epithelium of ectopic transplants (Fig. 4).

Several morphometric parameters were used to objectify microscopic examination and functional activity of the cells. They include determination of the glandular epithelium cellular height, determination of the height of the secretory part of glandular epithelium cells, determination of the nucleus area, carrying out densitometry of the nucleus and cells in general.

Statistical processing and analysis of morphometric examination of histological specimens resulted in the following. The height of secretory endometrioid epitheliocytes was significantly lower $(p<0.0001)$ only when cabergoline was used. No significant difference was found in case of cabergoline and celecoxib combination, and with celecoxib alone (Fig. 5).

The following regularity was found after examination of a secretory part of epitheliocytes: a reliable decrease was observed only with the use of cabergoline. No significant difference was found in the use of cele-

\section{Types of lesions}

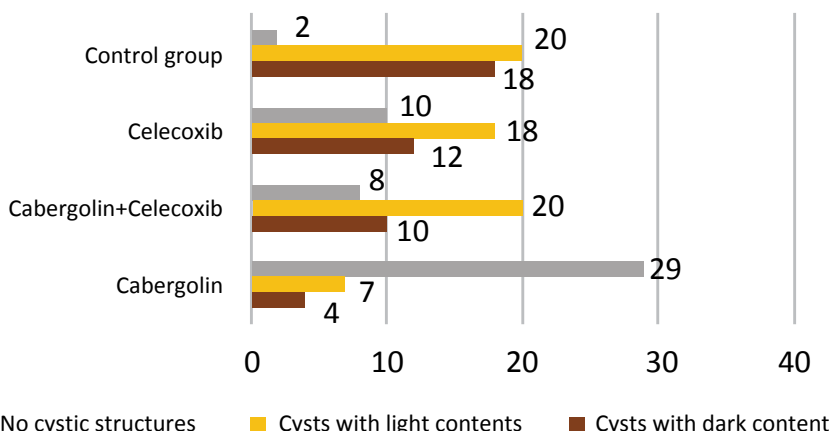

Fig. 2. Types of experimental endometriosis lesions on the peritoneum in experimental groups.

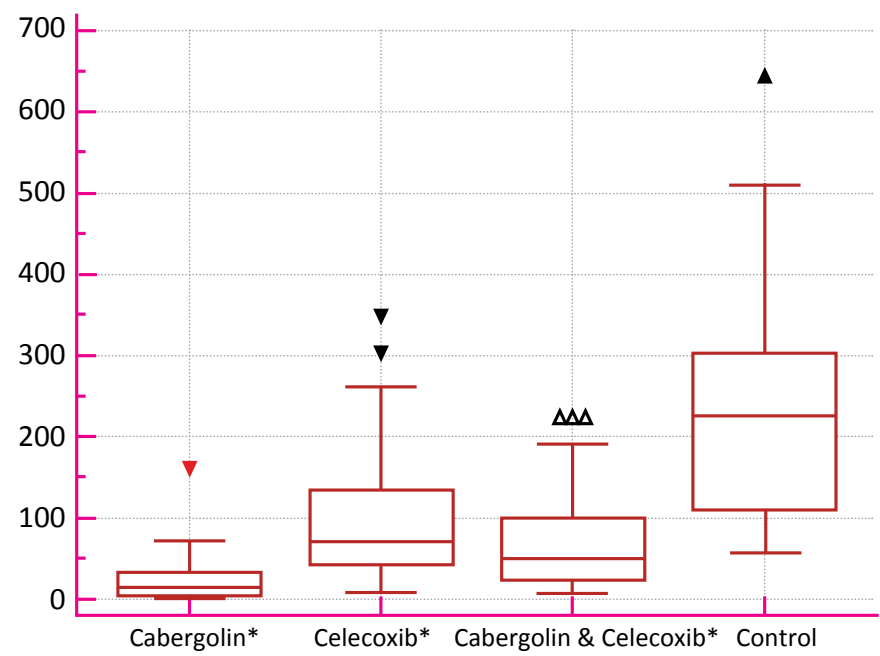

A Fig. 3. Average volume of experimental endometriosis lesions on the peritoneum in experimental groups, $\mathrm{mm}^{3}$.

Note: * $-p<0.0001$ compared to control group;

$\boldsymbol{\nabla} \boldsymbol{\Delta}$ - extreme outliers.

coxib, and in case of cabergoline and celecoxib combination, a significant increase in the secretory portion of epitheliocytes was detected.

The determined area of the epitheliocyte nucleus (Fig. 6) was significantly smaller in all the experimental groups (without a significant difference between the experimental groups) compared to the control. Morphometry of samples from the control group of animals revealed a smaller nucleus compared to that of the eutopic endometrium.

A relative densitometric density of epitheliocyte nuclei was significantly $(p<0.05)$ higher (indicating less compacting of nuclei) in all the experimental groups compared to that of the control one. However, in fact, it was equal to a relative nucleus density of eutopic epitheliocytes. Determination of the relative density of epitheliocytes did not reveal a significant difference $(p>0.05)$ between the experimental groups and the control group.

According to current literature data, we suggest that the effectiveness (according to the above mentioned indices) of cabergoline administration in experimental endometriosis compared with that of the control group is caused by its direct effect on dopamine D2 receptors. In its turn, it activates phosphorylation of VEGF receptors and their internalization via the adenylate cyclase pathway, which directly blocks the action of VEGF further leading to inhibition of angiogenesis. Due to inability to form new vessels, with nutrient and oxygen deficiency, the ectopic endometrioid 

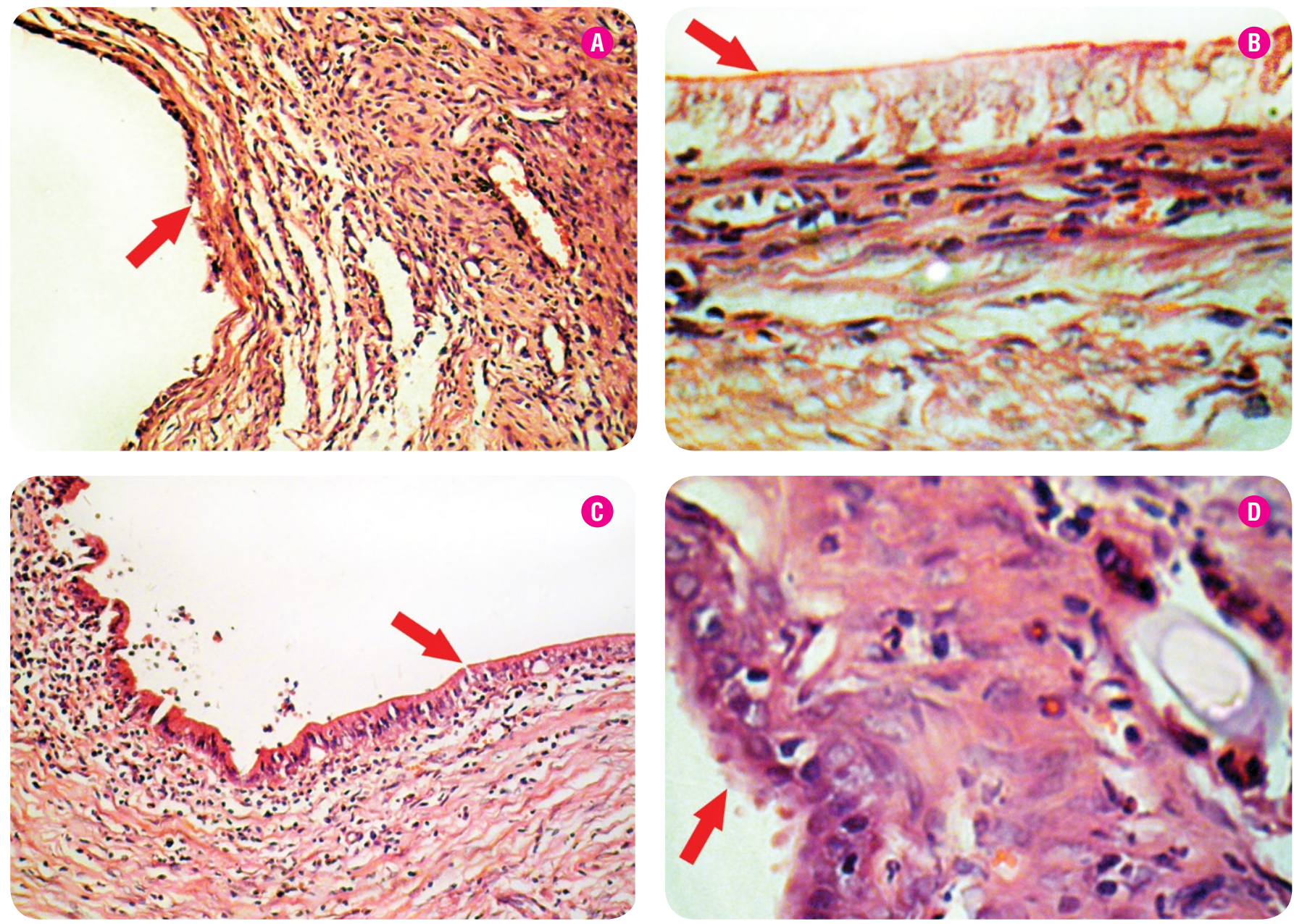

Fig. 4. Microscopic views of ectopic uterine tissue on the peritoneum in rats when using cabergoline (A), celecoxib (B) or combination of cabergoline and celecoxib (C) compared to control group (D). Arrow indicates secretory epithelium. Hematoxylin and eosin stain. 0b. 10x (A, C) and 40x (B, D), 0c. 10x

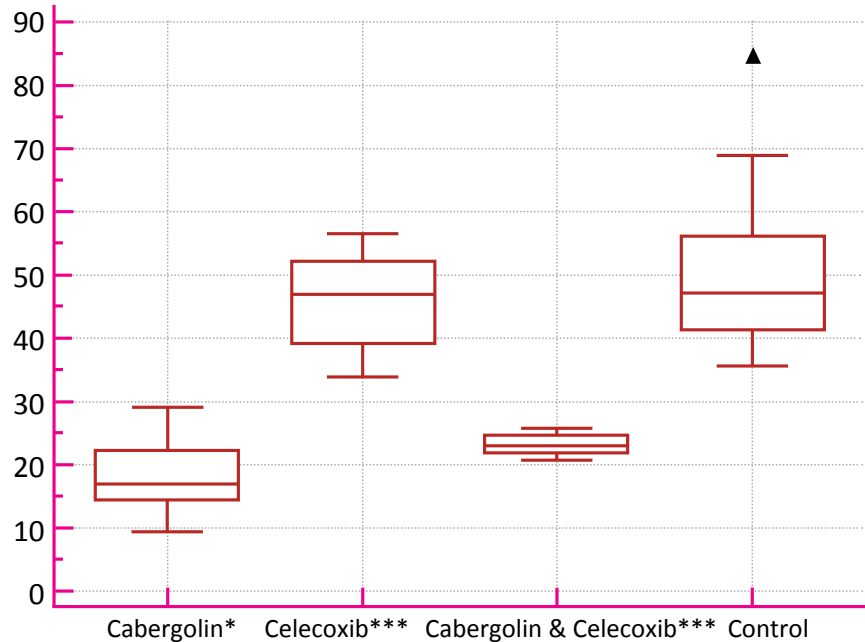

Fig. 5. Height of epitheliocytes in ectopic endometrium on experimental endometriosis, $\mu \mathrm{m}$

Notes: ${ }^{*}-p<0.0001$ compared to control group; ${ }^{* * *}-p>0.05$ compared to control group; $\mathbf{\Delta}$-extreme outliers.

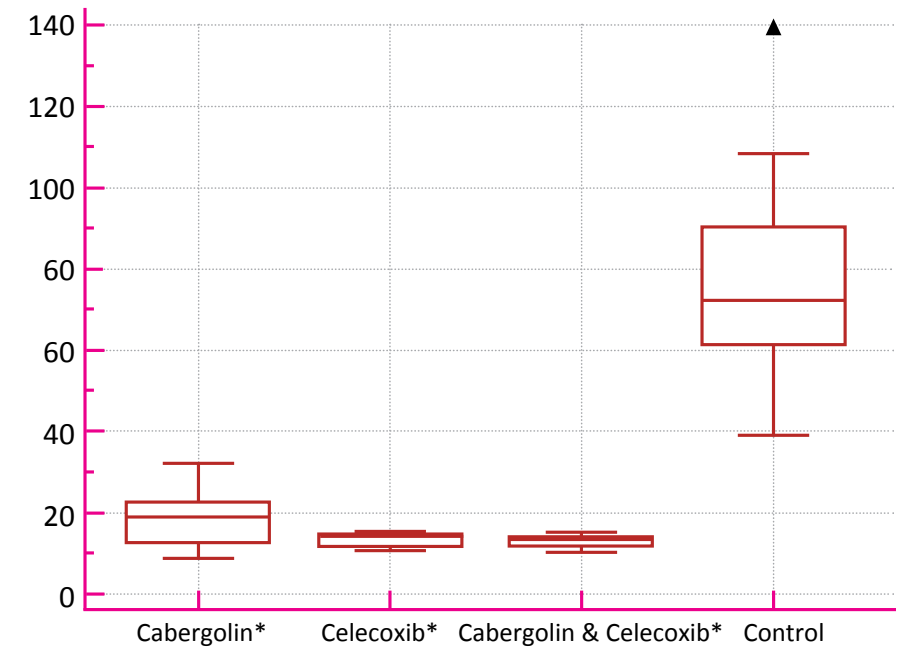

A Fig. 6. Nucleus area of epitheliocytes in ectopic endometrium on experimental endometriosis, $\mu \mathrm{m}^{2}$

Note: * $-p<0.0001$ compared to control group; $\mathbf{\Delta}$-extreme outliers 
implant has no potential for further development and secretory activity. This is confirmed by the data indicating decrease in epitheliocytes and their secretory poles in size, as well as the compacting of the epitheliocyte nuclei.

According to the theoretical data reported in the relevant publications, COX-2 inhibitors potentially produce an inhibitory effect on angiogenesis by deactivating PGE2 formation, which, in the opinion of many authors, is responsible for an alternative (non-VEGF) pathway of angiogenesis. However, as indicated by our study, the use of celecoxib in experimental endometriosis in rats did not produce the expected efficacy. Despite a significant reduction of lesions in size (although less significant than after cabergoline use), the size of epitheliocytes, their secretory part remained unchanged. Moreover, endometrioid lesions predominate in this group in the form of cystic structures, including almost $1 / 3$ of them with a dark content confirming their activity. Apparently blocking non-VEGF pathways of angiogenesis is insufficient to suppress the growth of endometrioid lesions in the experiment. A similar statement is found in Xu et al. [69], where the authors did not obtain the expected results when using highly selective COX-2 inhibitors to inhibit tumor angiogenesis. Obviously, a possible role and time-related effects of the use of highly selective COX-2 inhibitors in endometriosis should be investigated.

A complex administration of cabergoline, a dopamine receptor agonist, and celecoxib, a highly selective COX-2 inhibitor, similar to that of the previous group (using celecoxib alone) did not produce the expected efficacy, despite a noticeable efficacy of cabergoline alone. Although an average volume of lesions is significantly smaller than that in the control group, the size of epitheliocytes did not decrease significantly compared to the control, and their secretory part is even larger than in the control group. After administration of both cabergoline in combination with celecoxib, and celecoxib alone, vacuolation of epitheliocytes was observed, as it is evidenced by an increased rate of relative cell density. At the same time, compaction of epitheliocyte nuclei was observed. These data indicate insufficient inhibition of endometrial cell functional activity and, therefore, insufficient regression of endometrioid ectopic foci.

Despite a theoretically expected synergistic effect of cabergoline and celecoxib, the results of our study are indicative of its lack. Similar conclusions were also drawn by Xu et al. (2015) [69]. In this study, bevacizumab (a direct specific VEGF blocker) in combination with celecoxib was shown to have much less effectiveness in blocking tumor angiogenesis than in a single administration. At the same time, in a separate administration, celecoxib showed less efficacy in blocking angiogenesis in tumors than bevacizumab.

Therefore, the use of a dopamine receptor agonist as a VEGF inhibitor in combination with a highly selective COX-2 inhibitor does not lead to potentiation or summation of their effects. At the same time, the use of the COX-2 inhibitor alone showed significantly lower efficacy than using the dopamine D2 receptor agonist as a VEGF inhibitor. On the basis of our study, the use of dopamine receptor agonists with the purpose to inhibit angiogenesis in endometriosis has real prospects for further study, including other animal models and the clinical studies.

\title{
CONCLUSION
}

\begin{abstract}
We identified that the use of a dopamine receptor agonist as a VEGF inhibitor separately produces a pronounced inhibitory effect on ectopic endometrioid formation. However, the use of dopamine receptor agonists in combination with a highly selective COX-2 inhibitor does not lead to potentiation or summation of their effects. At the same time, the use of the COX-2 inhibitor alone showed significantly less potency than the use of a dopamine receptor agonist as a VEGF inhibitor.
\end{abstract}

\section{REFERENCES}

1. Guidice LC. Endometriosis. Lancet. 2010; 362:2389-98. https://doi.org/10.1016/S0140-6736(04)17403-5.

2. Brown J, Farquhar C. An overview of treatments for endometriosis. JAMA. 2015; 313(3):296-8. http://doi.org/10.1001/jama.2014.17119.

3. Dunselman G, Vermeulen N, Becker C, Calhaz-Jorge C, D'Hooghe T, De Bie B, et al. ESHRE guideline: management of women with endometriosis. Hum Reprod. 2014; 29:400-12. https://doi.org/10.1093/humrep/det457.

4. Cheong YC, Smotra G, Williams AC. Non-surgical interventions for the management of chronic pelvic pain. Cochrane Database Systematic Review. 2014; 3. http://doi. org/10.1002/14651858.CD008797.pub2.

5. Novella-Maestre E, Carda C, Noguera J, Ruiz-Sauri A, Garcia-Valsce JA. Dopamine agonist administration causes a reduction in endometrial implants through modulation of angiogenesis in experimentally induced endometriosis. Hum Reprod. 2009; 24(5):1025-35. https://doi.org/10.1093/humrep/den499.

6. Olivares C, Ricci A, Bilotas M, Baranao R, Meresman G. The inhibitory effect of celecoxib and rosiglitazone on expermimental endometriosis. Fertil Steril. 2011; 96(2):428-33. https://doi.org/10.1016/j.fertnstert.2011.05.063.

7. Hashim HA. Potential role of aromatase inhibitors in the treatment of endometriosis. Int J Womens Health. 2014; 6:671-80. https://dx.doi.org/10.2147\%2FIJWH. S34684.

8. Macer ML, Taylor HS. Endometriosis and Infertility: A review of the pathogenesis and treatment of endometriosis-associated infertility. Obstet Gynecol Clin North Am. 2012; 39(4):535-49. https://doi.org/10.1016/j.ogc.2012.10.002.

9. Laux-Biehlmann A, d'Hooghe T, Zollner T. Menstruation pulls the trigger for inflammation and pain in endometriosis. Trends Pharmacol Sci. 2015; 36(5):270-6. https:// doi.org/10.1016/.tips.2015.03.004

10. Ranney B. Endometriosis: pathogenesis, sympyoms, and findings. Clin Obstet Gynecol.1988; 23(3):865-74.

11. Donnwez J. Endometriosis: pathogenesis and pathophysiology. New Jersey: RW Shaw, 1990:120-128.

12. Lu Z, Zhang $W$, Jiang $S$, Zou J, Li Y. Effect of oxygen tensions on the proliferation and angiogenesis of endometriosis heterograft in severe combined immunodeficiency mice. Fertil Steril. 2014; 101(2):568-76. https://doi.org/10.1016/j.fertnstert.2013.10.039.

13. Suzin J, Duechler M, Szuławska A, Czyż M, Kowalczyk-Amico K. Evaluation of selected angiogenic and inflammatory markers in endometriosis before and after danazol treatment. Reprod Fertil Dev. 2014; 26(3):414-20. https://doi.org/10.1071/RD12258.

14. Folman J, Shing Y. Angiogenesis. J Biol Chem. 1992; 267(16):10931-4.

15. Machado D, Palumbo AJ, Santos J, Mattos R, dos Santos T, Seabra S, et al. A GFP endometriosis model reveals important morphological characteristics of the angiogenic process that govern benign and malignant diseases. Histol Histopathol. 2014; 29(7):903-12. https://doi.org/10.14670/HH-29.903. 
16. Risau W. Mechanisms of angiogenesis. Nature. 1997; 386(6626):671-4.

17. Ferrara N. VEGF and the quest for tumour angiogenesis factors. Nat Rev Cancer. 2002; 2(10):795-803.

18. Nisolle M, Casanas-Roux F, Anaf V, Mine JM, Donnez J. Morphometric study of the stromal vascularization in peritoneal endometriosis. Fertil Steril. 1993; 59(3):681-4. https://doi.org/10.1016/S0015-0282(16)55823-3.

19. Shifren JL, Tseng JF, Zaloudek CJ. Ovarian steroid regulation of vascular endothelial growth factor in the human endometrium: implications for angiogenesis during the menstrual cycle and in the pathogenesis of endometriosis. J Clin Endocrinol Metab. 1996; 81(8):3112-8.

20. Hoeben A, Landuyt B, Highley MS, Wildiers H, van Oosterom AT, de Bruijn EA. Vascular endothelial growth factor and angiogenesis. Pharmacol Rev. 2004; 56(4):54980. https://doi.org/10.1124/pr.56.4.3.

21. Sharkey AM, Day K, McPherson A. Vascular endothelial growth factor expression in human endometrium is regulated by hypoxia. J Clin Endocrinol Metab. 2000; 85(1):402-9.

22. McLaren J, Prentice A, Charnock-Jones DS, Smith SK. Vascular endothelial growth factor (VEGF) concentrations are elevated in peritoneal fluid of women with endometriosis. Hum Reprod. 1996; 11(1):220-3.

23. Donnez J, Smoes P, Gillerot S, Casanas-Roux F, Nisolle M. Vascular endothelial growth factor (VEGF) in endometriosis. Hum Reprod. 1998; 13(6):1686-90.

24. McLaren J, Prentice A, Charnock-Jones DS. Vascular endothelial growth factor is produced by peritoneal fluid macrophages in endometriosis and is regulated by ovarian steroids. J Clin Invest. 1996; 98(2):482-9.

25. Bedaiwy MA,DahoudW, Skomorovska-ProkvolitY, YiL, LiuJH, Falcone T, etal. Abundance and Localization of Progesterone Receptor Isoforms in Endometrium in Women With and Without Endometriosis and in Peritoneal and Ovarian Endometriotic Implants. Reprod Sci. 2015; 22(9):1153-61 https://doi.org/10.1177/1933719115585145.

26. Leung DW, Cachianes G, Kuang WJ, Goeddel DV, Ferrara N. Vascular endothelial growth factor is a secreted angiogenic mitogen. Science. 1989; 246:1306-9.

27. Keck PJ, Hauser SD, Krivi G, Sanzo K, Warren T, Feder J. Vascular permeability factor, an endothelial cell mitogen related to. Science. 1989; 246:1309-12.

28. Parick $A A$, Ellis $L M$. The vascular endothelial growth factor family and its receptors. Hematology/Oncology Clinics of North America. 2004; 18:951-71. https://doi. org/10.1016/j.hoc.2004.06.004.

29. Ferrara N. Vascular endothelial growth factor: basic science and clinical progress. Endoc Rev. 2004; 25:581-611. https://doi.org/10.1210/er.2003-0027.

30. Carmeliet $P$, Ferreira V, Breier G, Pollefeyt S, Kieckens L. Abnormal blood vessel development and lethality in embryos lacking a single VEGF allele. Nature. 1996; 380:435-9.

31. Ferrara N, Carver-Moore K, Chen H, Dowd M, Lu L. Heterozygous embryonic lethality induced by targeted inactivation of the VEGF gene. Nature. 1996; 380:439-42.

32. Pepper MS, Ferrara N, Orci L, Montesano R. Potent synergism between vascular endothelial growth factor and basic fibroblast growth factor in the induction of angiogenesis in vitro. Biochem Biophys Res Commun. 1992; 189:824-31.

33. Ferrara N. Role of vascular endothelial growth factor in physiologic and pathologic angiogenesis: therapeutic implications. Semin Oncol. 2002; 29:10-4.

34. Cardones AR, Lionel LB. VEGF Inhibitors in Cancer Therapy. Curr Pharm Des. 2006; 12:387-94. https://doi.org/10.2174/138161206775201910.

35. Basu S, Nagy JA, Pal S, Vasile E, Eckelhoefer IA, Bliss VS. et al. Dopaminergic receptors linked to adenylate cyclase in human cerebromicrovascular endothelium. Nat Med. 2001; 7(5):569-74.

36. Bacic F, Uemtsu S, McCarron RM, Spatz M. Dopaminergic receptors linked to adenylate cyclase in human cerebromicrovascular endothelium. J Neurochem. 1991; 57:1774-80.

37. Graybiel AM, Hirsch EC, Agid Y. The nigrostriatal system in Parkinson's disease. Adv Neurol. 1990; 53:17-29.

38. Goldstein M, Deutch AY. Dopaminergic mechanisms in the pathogenesis of schizophrenia. FASEB. 1992; 6:2413-21.

39. Olanow CW, Tatton WG. Etiology and pathogenesis of Parkinson's disease. Annu Rev Neurosci. 1999; 22:123-44.

40. Egan MF, Weinberger DR. Neurobiology of schizophrenia. Curr Opin Neurobiol. 1997; 7:701-7.

41. Wick MM. 3,4-Dihydroxybenzylamine: a dopamine analog with enhanced antitumor activity against B16 melanoma. JNCl. 1979; 63:1465-7.

42. Wick MM. Levodopa and dopamine analogs: melanin precursors as antitumor agents in experimental human and murine leukemia. Cancer Treat Rep. 1979; 63:991-7.

43. Wick MM. Levodopa and dopamine analogs as DNA polymerase inhibitors and antitumor agents in human melanoma. Cancer Res. 1980; 40:1414-8.

44. Dasgupta PS, Lahiri T. Antitumor effect of i.p. dopamine in mice bearing Ehrlich ascites carcinoma. J Cancer Res Clin Oncol. 1987; 113:363-8.

45. Ricci A, Collier WL, Amenta F. Pharmacological characterization and autoradiographic localization of dopamine receptors in the portal vein. J Auton Pharmacol. 1994; 14:61-8.

46. Bacic F, Uematsu S, mcCarron RM, Spatz M. Dopaminergic receptors linked to adenylate cyclase in human cerebromicrovascular endothelium. J Neruchem. 1991; 57:1774-80.

47. Brown L. Vascular permeability factor/vascular endothelial growth factor: a multifunctional angiogenic cytokine. In: Goldberg I, Rosen E, editors. Regulation of Angiogenesis. Basel, Switzerland: Birkhauser; 1997.

48. Dvorak HF, Nagy JA, Feng D, Brown LF, Dvorak AM. Vascular permeability factor/vascular endothelial growth factor and the significance of microvascular hyperpermeability in angiogenesis. Cur Top Microbiol Immunol. 1999; 237:97-132.

49. Ahn SH, Monsanto SP, Miller C, Singh SS, Thomas R, Tayade C. Pathophysiology and Immune Dysfunction in Endometriosis. BioMed Res Int. 2015; 2015:12. http:// dx.doi.org/10.1155/2015/795976.

50. King C, Barbara C, Prentice A, Brenton J, Charnock-Jones D. Models of endometriosis and their utility in studying progression to ovarian clear cell carcinoma. J Pathol. 2015; 238(2):185-96. https://dx.doi.org/10.1002\%2Fpath.4657.

51. Ferrara N. Vascular endothelial growth factor: molecular and biological aspects. Cur Top Microbiol Immunol. 1999; 237:1-30.

52. Turner HE. Angiogenesis in pituitary adenomas—relationship to endocrine function, treatment and outcome. J Endocrinol. 2000; 165:475-81.

53. Nagai Y. Plasma levels of vascular endothelial growth factor in patients with acromegaly. Horm Metab Res. 2000; 32:326-9.

54. Berkman RA, Oldfield RH. Expression of vascular permeability factor / vascular endothelial growth factor gene in central nervous system neoplasms. J Clin Invest. 1993; 91:153-9.

55. Sahin M, Sahin E, Gumus/u S. Cyclooxygenase-2 in cancer and angiogenesis. Angiology. 2009; 60:242-53. https://doi.org/10.1177/0003319708318378.

56. Sinha P, Clements VK, Fulton AM, Ostrand-Rosenberg S. Prostaglandin E2 promotes tumor progression by inducing myeloid-derived suppressor cells. Cancer Res. 2007; 67:4507-13.

57. Wu G, Luo J, Rana JS, Laham R, Sellke FW, Li J. Involvement of COX-2 in VEGF-induced angiogenesis via P38 and JNK pathways in vascular endothelial cells. Cardiovasc Res. 2006; 69:512-9. https://doi.org/10.1016/j.cardiores.2005.09.019. 
58. Fukuda R, Kelly B, Semenza GI. Vascular endothelial growth factor gene expression in colon cancer cells exposed to prostaglandin E2 is mediated by hypoxia-inducible factor 1. Cancer Res. 2003; 63:2330-4.

59. Basu S, Nagy JA, Pal S, Vasile E, Eckelhoefer IA, Bliss VS, et al. The neurotransmitter dopamine inhibits angiogenesis induced by vascular permeability factor/vascular endothelial growth factor. Nat Med. 2001; 7:569-74.

60. Bhattacharya $R$, Sinha $S$, Yang SP, Patra $C$, Dutta $S$, Wang $E$. The neurotransmitter dopamine modulates vascular permeability in the endothelium. JMS. 2008; 3(14):112-8. https://dx.doi.org/10.1186\%2F1750-2187-3-14.

61. Teunis MA, Kavelaars A, Voest E, Bakker JM, Ellenbroek BA, Cools AR. Reduced tumor growth, experimental metastasis formation, and angiogenesis in rats with a hyperreactive dopaminergic system. FASEB Journal. 2002; 16:1465-7.

62. Sinha S, Vohra PK, Bhattacharya R, Dutta S, Sinha S. Dopamine regulates phosphorylation of VEGF receptor 2 by engaging Src-homology-2-domain-containing protein tyrosine phosphatase 2. J Cell Sci. 2009; 122:3385-92. https://doi.org/10.1242/jcs.053124.

63. Golan A, Winston RM, Dragenio R. Experimental endometriosis: a microsurgical animal model in rats. Isr J Med Sci. 1984; 20:1094-6. http://dx.doi.org/10.1590/ S0102-86501997000400003.

64. Hirata $T$, Osuga $Y$, Yoshino 0 , Hirota $Y$, Harada $M$, Takemura $Y$, et al. Development of an experimental model of endometriosis using mice that ubiquitously express green fluorescent protein. Hum Reprod. 2005; 20:2092-6. https://doi.org/10.1093/humrep/dei012.

65. Elgamal AD, Othman E-ER, Agmed FS. Ultrastructural Features of Eutopic Endometrium in a Rat Model of Endometriosis. JMAU. 2016; 4(1):20-7. https://doi. org/10.1016/j.jmau.2015.10.002.

66. Rezende $A C$, Silva $L A$, Junior LJ, Gobbi H, Martins MM. Experimental model for endometriosis. Comparative histological study between the ectopic and eutopic endometrium. Acta Cir Bras. 1997; 12(4):226-30. http://dx.doi.org/10.1590/S0102-86501997000400003.

67. Neto JN, Torres OJ, Coelho TM, Junior JN. Evaluation of the macroscopic growth degree of experimental endometriosis in rats. Acta Chir Brazil. 2007; 22(1):250-8. https://doi.org/10.1590/S0102-86502007000700003.

68. Amaral VF, Lago EA, Kondo W, Guarita-Souza LC, Francisco JC. Development of an experimental model of endometriosis in rats. Rev Col Bras Cir. 2009; 36(3):120-5. https://doi.org/10.1093/humrep/dei012.

69. Xu L, Stevens J, Hilton MB, Seaman S, Conrads TP, Veenstra T, et al. COX-2 Inhibition Potentiates Antiangiogenic Cancer Therapy and Prevents Metastasis in Preclinical Models. Sci Transl Med. 2015; 6(242):1-12. http://doi.org/10.1126/scitranslmed.3008455. 